\title{
LIGNIN-MODIFYING ENZYMES OF PLEUROTUS OSTREATUS GROWN ON AGRO-RESIDUES
}

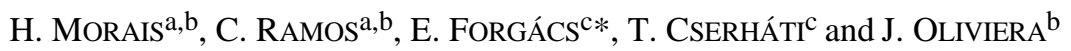

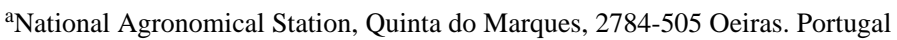 \\ ${ }^{b}$ New University of Lisbon, 2825 Monte da Caparica. Portugal \\ ${ }^{\mathrm{c} I n s t i t u t e}$ of Chemistry, Chemical Research Center, Hungarian Academy of Sciences, \\ H-1525 Budapest, P.O. Box 17. Hungary
}

(Received: 14 November 2000; accepted: 27 June 2001)

\begin{abstract}
The activity of lignin peroxidase (LiP) and laccase produced by Pleurotus ostreatus in culture media composed of agro-residues was measured by spectrophotometry. The overall enzyme activity and its dependence on the composition of culture media were determined by using spectral mapping technique followed by non-linear mapping. The relationships between the parameters of enzyme production and the composition of culture media and fermentation time were assessed by stepwise regression analysis. It was established that $P$. ostreatus did not produce LiP. The lowest enzyme production was observed in culture media containing extract of wheat straw. This finding indicates that the use of other agro-residues as substitutes for wheat straw is justified. It was further established that the enzyme production was also influenced by the $\mathrm{pH}$ of the culture media. It was found that enzyme activity quadratically depended on the fermentation time.
\end{abstract}

Keywords: Pleurotus ostreatus, spectral mapping, nonlinear mapping

Lignin is the earth's second most abundant polymer ranking only behind cellulose in quantity as a natural biopolymer (CRAWFORD, 1981). It is composed primarily of phenylpropanoid monomeric units interconnected by a complex array of stable carboncarbon and carbon oxygen bonds (ADLER, 1977). Lignin is highly stable under natural conditions, therefore, its biodegradation is one of the rate-limiting steps in the global carbon cycle.

Mushrooms generally produce a wide range of extracellular enzymes which degrade complex lignocellulosic substrates into soluble substances of considerable nutritive value. White-rot fungi are the most efficient ligninolytic microorganisms in nature. They have evolved a unique mechanism to accomplish the degradation of lignin

* To whom correspondence should be addressed.

Fax: 36-1-325-7554; E-mail: forgacs@ cric.chemres.hu 
employing extracellular enzymes to generate oxidative radicals (EvANS et al., 1994). This enzyme system is highly nonspecific, therefore, these fungi can oxidise a broad spectrum of structurally diverse compounds (FIELD et al., 1993). Oxidation process involves various enzymes such as lignin peroxidase (LiP), manganese-dependent and manganese-independent peroxidase, laccase, etc. (KIRK \& FARRELL, 1987).

LiP attacks both phenolic and non-phenolic aromatic structures the latter giving rise to cationic radicals that fragment spontaneously (KERSTEN et al, 1985). Laccase, a copper-containing phenoloxidase catalyses the four-electron reduction of oxygen to water and it is accompanied by the oxidation of the phenolic substrate (THURSTON, 1994). However, the substrate range of laccase has been recently extended to include non-phenolic lignin subunits in the presence of readily oxidizable primary substrates (mediators). It was found that in the presence of 2,2'-azinobis-(3-ethylthiazoline-6sulfonate) as mediator laccase oxidizes non-phenolic model lignin compounds (BOURBOnNAIS \& PAICE, 1990) and polycyclic aromatic hydrocarbons (COLLINS et al., 1996), and enhances the delignification rate of pulp (BOURBONNAIS et al., 1995).

Pleurotus ostreatus, an edible basidiomycete is also able to degrade wood. Its growth and fruiting are dependent largely upon the capacity to utilise cellulose, hemicellulose and other ligno-cellulosic raw materials as a nutritional source. Because of the outstanding importance of lignin decomposition the possible application of Pleurotus ostreatus in various biotechnological processes is of both theoretical and practical importance.

The objectives of the study were the determination of the production of LiP and laccase activity during the complete life cycle of $P$. ostreatus cultivated in liquid media composed of agro-industrial residues as the sole source of carbon and nitrogen; the application of multivariate mathematical statistical methods for determining the overall activity and selectivity of enzyme production; and the elucidation of the relationships between the composition of the fermentation media and the characteristics of enzyme production. The results may contribute to the better understanding of the underlying biochemical and biophysical processes and can find potential applications in the biotransformation of lignocellulose biomass.

\section{Materials and methods}

\subsection{Materials}

Sodium tartarate and hydrogen peroxide were purchased from Merck KGaA (Darmstadt, Germany); 2,6-dimethoxyphenol (99\%, GC) and 3,4-dimethoxybenzyl alcohol (veratryl alcohol) were purchased from Sigma-Aldrich GmbH (Steinheim, Germany). Each chemical was used as received. 


\subsection{Organism and culture conditions}

The strain of $P$. ostreatus was taken from the collection of the National Agronomical Station (Oeiras, Portugal). It was maintained on potato dextrose agar (PDA) (Merck KGaA). Dry industrial residues of the production of red pepper (Capsicum апnиum, dry matter $85.66 \%$ ) and potato (dry matter 91.15\%) (further pepper and dry potato) were used to substitute wheat straw generally used for the commercial scale production of $P$. ostreatus. Extracts of pepper ( $350 \mathrm{~g} \mathrm{l}^{-1}$ tap water), dry potato (560 $\mathrm{g} \mathrm{l}^{-1}$ tap water) and wheat straw ( $45 \mathrm{~g} \mathrm{l}^{-1}$ tap water) were prepared by cutting the raw materials into small pieces (approximately 4 mesh) and adding the appropriate quantity of water. The use of higher concentrations of pepper and dry potato for the extraction procedure was motivated by the fact that higher concentration of wheat straw cannot be used because it adsorbs all water. The use of higher concentrations of pepper and potato residues may result in elevated enzyme production of $P$. ostreatus. The mixtures were let to stay for $24 \mathrm{~h}$ at $18 \pm 2{ }^{\circ} \mathrm{C}$ without stirring. After extraction the suspensions were filtered on a Whatman No 1 filter paper then were centrifuged at $2 \cdot 10^{4} \mathrm{~g}$ for $20 \mathrm{~min}$. The use of supernatants instead of the whole broth was motivated by the consideration that the sampling of liquid cultures is more precise than that of a broth, containing both liquid and solid phases. In order to determine the nutritive value of the culture media, the concentrations of total phenolics, total and reducing sugars were measured. The composition and initial $\mathrm{pH}$ of the culture media are listed in Table 1. Initial $\mathrm{pH}$ of the culture media was measured with a $\mathrm{pH} / \mathrm{mV}$ Meter Digit 501 (Crison, Barcelona, Spain) between glass and kalomel electrodes. Liquid medium for the cultivation of $P$. ostreatus was prepared by mixing $200 \mathrm{ml}$ of extract and $200 \mathrm{ml}$ of distilled water in an 1-1 Erlenmeyer flask. The medium was sterilized at $121^{\circ} \mathrm{C}$ for $20 \mathrm{~min}$, cooled to $26^{\circ} \mathrm{C}$ and inoculated by adding a piece of agar of about $10 \mathrm{~mm}$ diameter with micelium. The cultures were incubated at $24 \pm 2{ }^{\circ} \mathrm{C}$ in the dark for 30 days then were transferred to a fructification room and held at $18 \pm 2{ }^{\circ} \mathrm{C}, 12 \mathrm{~h}$ light/day for 33 days. Each seventh day sample was taken from the culture medium under sterile conditions and was centrifuged at $20.000 \mathrm{~g}$ for $20 \mathrm{~min}$, and the activity of LiP and laccase was determined by visible spectrophotometry. Each measurement was performed with a UNICAM 87000 Spectrophotometer (Cambridge, England) at $30^{\circ} \mathrm{C}$ in a cuvette of $10 \mathrm{~mm}$ length. As the $\mathrm{pH}$ exerts a considerable impact on the enzyme production, the $\mathrm{pH}$ of the samples were also determined by the method described above.

\subsection{Determination of enzyme activities}

Laccase $=$ reaction mixture contained $10 \mathrm{mM}$ 2,6-dimethoxyphenol in $100 \mathrm{mM}$ sodium tartarate $(\mathrm{pH} 5.0)$ and $300-600 \mu \mathrm{l}$ extracellular culture fluid in a total volume of $1 \mathrm{ml}$. 
Table 1

Composition and initial pH of culture media

\begin{tabular}{rcccc}
\hline No. compositions & $\begin{array}{c}\text { Total } \\
\text { phenols } \\
\left(\mu \mathrm{g} \mathrm{ml}^{-1}\right)\end{array}$ & $\begin{array}{c}\text { Total } \\
\text { sugars } \\
\left(\mu \mathrm{g} \mathrm{ml}^{-1}\right)\end{array}$ & $\begin{array}{c}\text { Reducing } \\
\text { sugars } \\
\left(\mu \mathrm{g} \mathrm{ml}^{-1}\right)\end{array}$ & $\mathrm{pH}$ \\
\hline I $\quad \begin{array}{l}\text { 0.5 straw extract, 0.3 pepper } \\
\text { extract, 0.2 potato extract }\end{array}$ & 30.2 & 201.9 & 136.3 & 7.20 \\
II $\begin{array}{l}\text { 0.5 straw extract, 0.2 pepper } \\
\text { extract, 0.3 potato extract }\end{array}$ & 21.8 & 158.0 & 85.6 & 7.69 \\
III $\begin{array}{l}\text { 0.5 straw extract, 0.4 pepper } \\
\text { extract, 0.1 potato extract }\end{array}$ & 35.8 & 228.4 & 195.5 & 7.22 \\
IV $\quad$ straw extract & 3.4 & 9.2 & 4.2 & 7.84 \\
V pepper extract & 85.8 & 563.2 & 399.5 & 6.31 \\
VI potato extract & 15.6 & 290.4 & 118.2 & 7.64 \\
\hline
\end{tabular}

The absorbance was measured at $469 \mathrm{~nm}$ after $5 \mathrm{~min}$ of incubation at $30{ }^{\circ} \mathrm{C}$. $\mathrm{LiP}=$ reaction mixture contained $0.54 \mathrm{mM} \mathrm{H}_{2} \mathrm{O}_{2}$ and $0.4 \mathrm{mM}$ veratryl alcohol in $100 \mathrm{mM}$ sodium tartarate $(\mathrm{pH} \mathrm{3.0)}$ ), and $500 \mu \mathrm{l}$ of extracellular culture fluid in a total volume of $1 \mathrm{ml}$. Absorbance was measured at $310 \mathrm{~nm}$ after 5,10 and $15 \mathrm{~min}$ of incubation at $30^{\circ} \mathrm{C}$.

\subsection{Evaluation of the enzyme activity data by multivariate mathematical-statistical methods}

No LiP activity was observed during the fermentation of $P$. ostreatus, therefore, the following calculations were performed only on the activity data of laccase. Data matrix for laccase activities contained the sampling days as variables (together 9 variables) and the composition of culture medium as observations (together 6 observations). In order to determine the overall activity and selectivity of enzyme production according to the composition of culture medium. Spectral mapping technique (SPM) was employed (LEWI, 1976; LEWI, 1989). The method divides the information into two matrices, using the logarithm of the original data. The first one is a vector containing the potency values related to the overall enzyme activity (quantitative measure of the effect of the composition of culture media). The second matrix (selectivity map) contains information on the spectra of activity (qualitative characteristics of the effect). As the evaluation of the multidimensional selectivity maps is difficult with traditional methods their dimensionality were reduced to two by nonlinear mapping technique (NLMAP) (SAMMON, 1969). The procedure projects the variables and observations (in our case fermentation media and fermentation time) on a plane in such a manner that the distances between the points should be approximately 
the same as in the original multidimensional space. The iteration was carried out to the point when the difference between the last two iterations was lower than $10^{-8}$. The potency values calculated by SPM refer to the overall enzyme production of culture media, whereas the distribution of culture media on the map reflects the selectivity of their effect on the enzyme production.

In order to study the effect of the duration of fermentation on the overall enzyme production and on its selectivity the same calculation was performed on the transposed matrix, too. The calculation of selectivity maps was carried out as described above. In this case the potency values refer to the overall enzyme production at the individual sampling times, whereas the distribution of the sampling times on the two-dimensional non-linear map reflects the selectivity of the enzyme production at different sampling times.

The relationship between the results of SPM, fermentation time and the composition of culture media was elucidated by stepwise regression analysis (MAGER, 1982). In the common multilinear regression analysis the inclusion of independent variables that exert no significant impact on the dependent variable lessens the significance level of independent variables that significantly influence the dependent variable. Stepwise regression analysis overcomes this difficulty by eliminating automatically from the selected equation the insignificant independent variables enhancing in this manner the information power of the calculation. The dependent variables were separately the potency values and the first and second coordinates of the two-dimensional non-linear selectivity maps calculated from the original and transposed data matrices, the independent variables being the days of fermentation, the composition and $\mathrm{pH}$ of the culture media. As the relationships between the calculated parameters and the days of fermentation were markedly non-linear, the square of the days of fermentation was also included. The number of accepted independent variables was not limited, the acceptance level was set to 95\% significance level.

Softwares for SPM and NLMAP were prepared by Dr. Barna Bordás (Plant Protection Institute of Hungarian Academy of Sciences, Budapest, Hungary). Software for stepwise regression analysis was purchased from Compudrug, Ltd. (Budapest, Hungary).

\section{Results and discussion}

LiP activity was not detected in any culture media during the fermentation process, indicating that $P$. ostreatus does not produce LiP in detectable amount. The activity values of laccase are compiled in Table 2 . The activity values show high variations, indicating that both the composition of culture media and the fermentation time exert a considerable influence on the activity of laccase. Similar results have been 
previously obtained, however, the authors used a different method for the determination of the laccase activity, therefore, the results cannot be compared (SANNIA et al., 1986). The potency values reflecting the effect of the composition of culture media and fermentation time on the overall activity of laccase are compiled in Table 3 . The results entirely support our previous qualitative conclusions, the potency values show high differences according to the composition of the culture media and the fermentation time. Furthermore, the results indicate that the effect of the composition of culture media and that of the fermentation time are commensurable.

The two-dimensional non-linear selectivity map of culture media is shown in Fig. 1. Culture media containing straw extract form a clear-cut cluster, whereas the points characterizing potato and pepper extracts are on the opposite end of the map. This finding suggests that the presence of straw extract in the culture media play a considerable role in the determination of the selectivity of the laccase production of P. ostreatus.

Table 2

Laccase production of Pleurotus ostreatus (nanomol $\mathrm{min}^{-1} \mathrm{ml}^{-1}$ ) and the $\mathrm{pH}$ of the samples. Roman numbers refer to culture media in Table 1

Laccase production

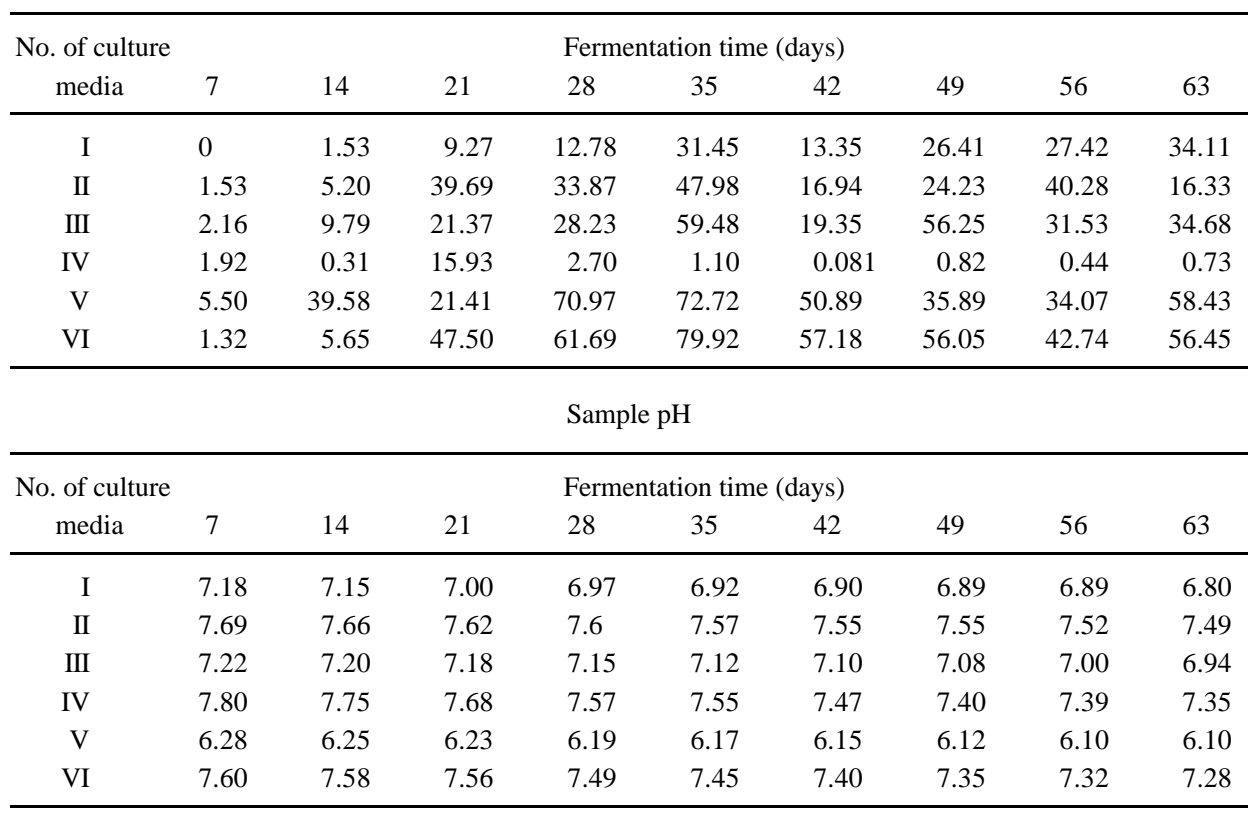


Table 3

Effect of the composition of culture media and fermentation time on the activity of laccase production of Pleurotus ostreatus. Potency values (arbitrary units) calculated by SPM. Roman numbers refer to culture media in Table 1

\begin{tabular}{cccc}
\hline No. of culture media & Potency & Fermentation days & Potency \\
\hline I & 52.11 & 7 & 5.07 \\
II & 74.35 & 14 & 25.34 \\
III & 87.61 & 21 & 62.12 \\
IV & 8.01 & 28 & 85.83 \\
V & 129.82 & 35 & 119.47 \\
VI & 136.17 & 42 & 64.42 \\
& & 49 & 81.51 \\
& & 56 & 72.05 \\
\end{tabular}

The two-dimensional non-linear selectivity maps of the fermentation time are shown in Fig. 2. The days of fermentation form two loose groups according to the length of fermentation. This finding suggests that the selectivity of enzyme production is similar in the first 21 days of fermentation then it changes and remain the same until the end of the fermentation process.

Stepwise regression analysis found significant linear relationships between the overall enzyme production (potency values), its selectivity (first and second coordinates of the two-dimensional non-linear selectivity maps $=\mathrm{spm}_{1}$ and $\mathrm{spm}_{2}$ ) and the composition of culture media and fermentation time.

Culture media $(\mathrm{n}=6)$ :

Potency $=133.3-124.7 \pm 15.3)$. amount of straw extract

$$
\mathrm{r}_{\text {calc }}=0.9711 \mathrm{r}_{99 \%}=0.9172
$$

$\mathrm{Spm}_{1}=-520.3+(93.0 \pm 17.7) \cdot \mathrm{pH}$ of the culture media

$$
r_{\text {calc }}=0.9343 r_{99 \%}=0.9172
$$

$\mathrm{Spm}_{2}=142.9-(130.6 \pm 33.9) \cdot$ amount of straw extract

$$
\mathrm{r}_{\text {calc }}=0.8873 \mathrm{r}_{99 \%}=0.8114
$$

Days of fermentation $(\mathrm{n}=9)$ :

$$
\begin{aligned}
& \text { Potency }=-31.4+(5.71 \pm 1.66) \text {.day }-(6.57 \pm 2.31) .10^{-2} .(\text { days })^{2} \\
& \qquad b^{\prime}{ }_{1} \%=54.75 ; b^{\prime}{ }_{2}=45.25 ; F_{\text {calc. }}=8.61 ; \mathrm{F}_{99.9 \%}=5.14
\end{aligned}
$$

No significant relationship was found between $\mathrm{spm}_{1}, \mathrm{spm}_{2}$ and the days of fermentation. 


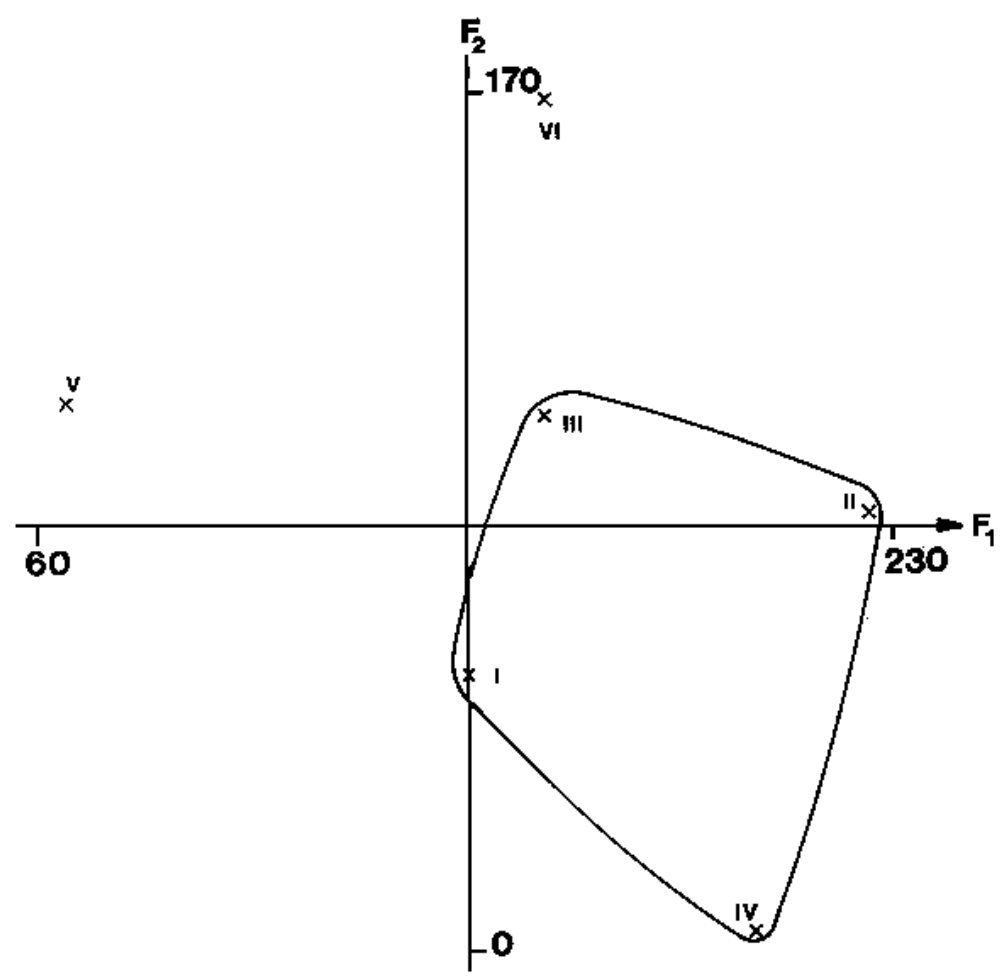

Fig. 1. Two-dimensional non-linear selectivity map of culture media based on the activity of laccase. Number of iterations: 119; maximum error: $2.5710^{-2}$. Roman numbers refer to culture media in Table 1

The data clearly show that the presence of straw extract decreases the overall activity of laccase. This finding indicates that the use of other agro-residues instead of the wheat straw may result in the increase of the enzyme production, therefore, their application as substitutes for wheat straw is justified. This finding is in accordance with the nutritive values in Table 1, where the nutritive value of wheat straw was the lowest. The negative regression coefficient indicates that the presence of straw extract significantly decrease the overall activity of laccase. The results further demonstrate that the selectivity of the laccase production depends on both the $\mathrm{pH}$ and the amount of straw extract of the culture media.

A quadratic correlation was found between the days of fermentation and the laccase production, the activity increased at shorter fermentation times and decreased near the end of fermentation process. 


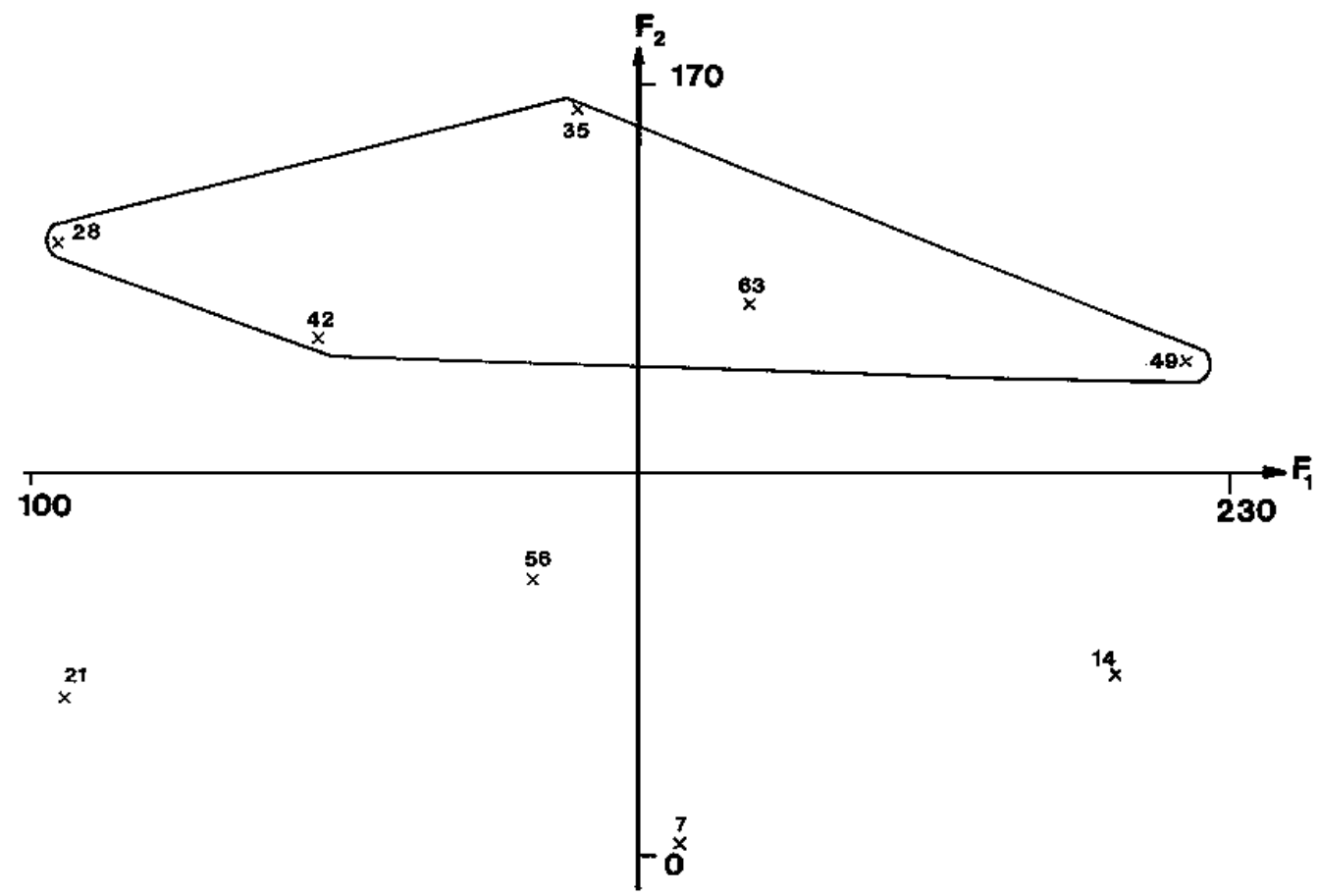

Fig. 2. Two-dimensional non-linear selectivity map of fermentation time based on the activity of laccase. Number of iterations: 89 ; maximum error: $3.8910^{-2}$. Numbers refer to fermentation days

\section{Conclusions}

The results proved that Pleurotus ostreatus produces laccase enzymes which is able to degrade lignin and related complex molecular structures. Because of this capacity $P$. ostreatus may find application in a variety of biotechnological processes. Calculations further proved that the overall enzyme production and its selectivity can be regulated by the composition of the culture media, containing only agro-residues as carbon and nitrogen sources. 
This work was supported by the Portuguese-Hungarian co-operation project 'Development of new methods and their application for the assessment of the effect of environmental conditions on the stability of color pigments in foods'.

\section{References}

ADLER, E. (1977): Lignin chemistry. Past, present and future. Wood Sci. Technol., 11, 169-218.

BourbonnAis, R. \& PAICE, M. G. (1990): Oxidation of non-phenolic substrates, an expanded role for laccase in lignin biodegradation. FEBS Lett., 267, 99-102.

Bourbonnais, R., Paice, M. G., ReID, I. D., Lanthier, P. \& Yaguchi, M. (1995): Lignin oxidation by laccase enzymes from Trametes versicolor and role of the mediator in kraft lignin depolymerization. Appl. environ. Microbiol., 61, 1876-1880.

Colling, P. J., Kotterman, M. J. J., Field, J. A. \& Dobson, A. D. W. (1996): Oxidation of anthracene and benzo[ $\alpha]$ pyrene by laccases for Trametes versicolor. Appl. environ. Microbiol., 62, 4563-4567.

CRAWFORD, R. L. (1981): Lignin biodegradation and transformation. Wiley Interscience, New York.

Evans, C. S., Dutton, M. V., Guillen, F. \& Veness, R. G. (1994): Enzymes and small molecular mass agents involved with ligno-cellulose degradation. FEMS microbiol. Rev., 13, 235-240.

Field, J. A., De Jong, E., Feijoo-Costa, G. \& De Bont, J. A. M. (1993): Screening for ligninolytic fungi applicable to the biodegradation of xenobiotics. Trends Biotechnol., 11, 44-49.

Kersten, P. J., Tien, M., Kalyanamaran, B. \& KirK, T. K. (1985): The ligninase of Phanerochaete chrysosporium generates cation radicals from methoxibenzenes. J. biol. Chem., 260, 2609-2612.

KIRK, T. K. \& FARRELL, R. L. (1987): Enzymatic combustion: the microbial degradation of lignin. Ann. Rev. Microbiol., 41, 65-505.

LEWI, P. J. (1976): Spectral mapping, a technique for classifying biological activity profiles of chemical compounds. Arzneimittel-Forsch., 26, 1295-1300.

LEWI, P. J. (1989): Spectral map analysis. Factorial analysis of contrast, especially from log ratios. Chenom. Intell. Lab. Syst., 5, 105-116.

MAgER, H. (1982): Moderne Regressionsanalyse. Salle, Sauerlander, Frankfurt am Main, pp. 135-157.

SAMmon, J. W. Jr. (1969): A non-linear mapping for data structure analysis. IEEE Trans. Comput., C18, 401-407.

SAnnia, G., Giardina, P., LunA, M. \& Bouncoure, V. (1986): Laccase from Pleurotus ostreatus. Biotechnol. Letters, 8, 797-800.

Thurston, C. F. (1994): The structure and function of fungal laccases. Microbiology, 140, 19-26. 